\title{
Book Review: Adapting Psychotherapy for an Underserved Population
}

\author{
Lorna Clark-Rubin, MD \\ Hahnemann University, Philadelphia PA
}

Follow this and additional works at: https://jdc.jefferson.edu/jeffjpsychiatry

Part of the Psychiatry Commons

Let us know how access to this document benefits you

\section{Recommended Citation}

Clark-Rubin, MD, Lorna (1987) "Book Review: Adapting Psychotherapy for an Underserved Population," Jefferson Journal of Psychiatry. Vol. 5 : Iss. 2 , Article 13.

DOI: https://doi.org/10.29046/JJP.005.2.012

Available at: https://jdc.jefferson.edu/jeffjpsychiatry/vol5/iss2/13

This Article is brought to you for free and open access by the Jefferson Digital Commons. The Jefferson Digital Commons is a service of Thomas Jefferson University's Center for Teaching and Learning (CTL). The Commons is a showcase for Jefferson books and journals, peer-reviewed scholarly publications, unique historical collections from the University archives, and teaching tools. The Jefferson Digital Commons allows researchers and interested readers anywhere in the world to learn about and keep up to date with Jefferson scholarship. This article has been accepted for inclusion in Jefferson Journal of Psychiatry by an authorized administrator of the Jefferson Digital Commons. For more information, please contact: JeffersonDigitalCommons@jefferson.edu. 


\title{
Book Review
}

\section{Adapting Psychotherapy for an Underserved Population}

\author{
PSYCHOTHERAPY IN THE COMMUNITY: \\ A PSYCHOANALYTICALLY BASED GUIDE \\ TO THE TREATMENT OF THE ADULT \\ Eric Lager, M.D., Israel Zwerling, M.D. \\ with Joseph Slap, M.D., Samuel Bullock, M.D. \\ Warren Smith, M.D. \\ Warren H. Green, Inc., St. Louis \\ 1983. $190 \mathrm{pp}$.
}

\section{Lorna Clark-Rubin, M.D.}

This is a book which could be considered by some with loyalties to the idealism of the community mental health movement to contain more than a little nostalgia. To put it in context, the case vignettes make reference to the several inner-city neighborhood satellite clinics, where community mental health patients are treated by Hahnemann University faculty, psychiatric residents, psychology interns, mental health worker trainees, social workers and permanent staff psychotherapists. As described in the vignettes, it was not unusual for patients to walk in without appointments, nor was it unusual for therapists to make home visits. This book is based on Hahnemann's experience of its intimate involvement in urban community mental health centers during the 1970's. This involvement had begun to shift even before this reviewer's residency at Hahnemann.

The book's introduction includes a review of the literature through 1978 on characteristics of the population served by community mental health, characteristics of successful therapists, and methods used in treatment. Following this review is a summary based on the author's personal experiences in supervision and case conferences, observation of therapy sessions, and the results of a questionnaire. The questionnaire, which was completed by therapists from various disciplines, seeks to identify factors associated with success and failure of treatment outcomes. Diagnosis and medications are not included

Dr. Clark-Rubin is a child psychiatry fellow at Hahnemann University, Philadelphia, Pennsylvania. 
among the information requested. Treatment failure is described as withdrawal, premature termination, or poor outcome. Success is described as treatment continuing to good outcome, either ongoing or terminated by mutual agreement. From two years of regular discussions based on this experience and information, the authors have distilled factors leading to success and failure in psychotherapy with this largely herein undefined group of patients from the urban ghetto. They have sought to identify those aspects of traditional psychoanalytically-oriented psychotherapy which are applicable. They describe modifications which are necessary for engagement of the patient and optimal outcome, and provide a psychoanalytic understanding of these modifications. What emerges is an impressionistic (there are no statistics, no diagnostic descriptions) but, I believe, fairly accurate portrayal of some of the difficulties encountered in working with a deprived population. The authors make a convincing and pragmatic argument for modifying the traditional posture of anonymity and abstinence. The therapy which emerges is not analysis, but rather a modified supportive and interpretive psychotherapy.

The book is organized into chapters on selecting the patient for long term psychotherapy and the beginning phase of treatment, the middle phase with its transference and countertransference issues, and termination. The descriptions include a number of clinical vignettes. The final chapter is a transcription of ten supervisory sessions between the principal author and an experienced therapist presenting a woman she began treating four years earlier. The reader unfamiliar with community psychiatry would find it more helpful to read this transcription first to orient himself to the type of patient being treated and to the level of involvement by the therapist which this work entails.

The goals of the psychotherapy described are supportive in the short term, often through various crises, but beyond this to provide a therapeutic relationship in which the patient can verbalize rather than act out, and gain insight. The expectation is that this may evolve into a therapy of long duration, since many patients will continue to need a supportive relationship, though some may be able to move toward discovering that intrapsychic difficulties may be a part of the external problems they have complained of.

The authors describe cultural value orientations of lower class patients and contrast these with the middle class orientation of many therapists. It is the therapist's ability to traverse these differences and let go of his ethnocentricity and prejudice, in addition to his skill and experience, which predicts a good outcome. Other therapist factors include genuineness and commitment to democratic values, respect for his own autonomy and that of others, and rejection of authoritarian control and direction. Also of great importance are the appropriate activity level of the therapist, his warmth, empathy, and willingness to spend time with the patient. The authors also suggest that pre-treatment instructions in psychotherapy are helpful to these patients because of their unfamiliarity with its goals and methods. The patient may hold 
the expectation that the therapist be authoritarian and work with him on solutions to reality problems. This may have to be gratified initially as the psychotherapeutic work moves toward helping the patient discover an internal causation of his difficulties.

Assessment of the patient's capacity to engage in a treatment relationship is an important consideration in any selection process for long term psychotherapy. In this population, this capacity can often be identified by the patient's having had a special relationship with a parent figure, perhaps an oedipal victory. The patient may then have an optimism about recreating this special relationship with the therapist.

The typical situation described is that of a patient whose premorbid function was dependent on access to a parental figure. After a loss of or disappointment in that figure, a period of time follows in which the patient has attempted unsuccessfully to regain that parenting relationship, often with a same age heterosexual partner or another relative. The patient may present, however, with complaints about current difficulties. The example given is that rage from loss of the parent figure may be mobilized as the urge to harm one's children. Often the parent figure is not the patient's mother-sometimes it is a grandmother or other relative. The middle class therapist may underestimate the significance of this person to the patient, misperceiving it as predominantly exploitive.

The loss or disappointment in this relationship may be more traumatic because of early deprivation and heightened needs for rewards and exclusivity in the present relationship. These heightened expectations may become mobilized toward the therapist. The patient's behavior expresses his need for the therapist to function as an authority figure and to provide help with reality problems. The patient's orientation is toward the here and now, not toward investment and delayed gratification in pursuing the goal of character change. The authors use the analogy of a psychological economy. In an economy of shortage, of low self-esteem, the patient has little to invest-the risk of rejection and possible loss is too great. Simple barriers - getting a babysitter, bus fare, walking more than a few blocks - may thus be insurmountable obstacles. The patient may be ready to withdraw even this small investment at any anticipated sign of rejection by the therapist, such as a cancelled appointment. The authors describe a consistent tendency of the therapist to undervalue his significance to the patient and thus fail to adequately deal with the patient's acting out around his absences. Above all, the patient must have enough hope for help to overcome the expected pain of coming for help and of self-disclosure, and enough hope to run the risk of perceived rejection. Accordingly, there may be a high early treatment dropout rate following the patient's disappointment in not being able to possess the therapist, or to his sensitivity to rejection by the therapist. In addition, the patient may have greater difficulty with self-revelation than someone from a middle class background. 
In summary, what is presented is a psychodynamic understanding of the vicissitudes of working with these patients, and a rationale for modifying one's approach from the traditional stance.

This book will be of interest to the therapist working with patients from a variety of backgrounds. It elucidates some patterns of early deprivation and suggests ways to modify the treatment to facilitate these patients' engagement while allowing for the psychotherapeutic work to move toward insight over action in a context of basic trust. It recognizes that the therapist must be willing to become both transference object and real person to his patient, and that he must carefully tailor his interventions to what the patient needs and can tolerate. A weakness of the presentation is that it is blind to diagnosis, severity of impairment, and ego assessment, thus leaving the reader uncertain as to an accurate description of the patients being treated. The clinical vignettes and transcript of supervision in the last chapter do provide some anecdotal information toward clarifying this point.

Urban community mental health has undergone many changes since the 1970 's. Psychotherapy as described here may no longer be available in urban clinics. In recent years, some of the last satellite clinics have been closed and been centralized. Some of us at Hahnemann had the painful burden of participating in the university's withdrawal from urban outpatient mental health programs. Changing economic and political realities, a clinically naive, community-governed board of directors with a severely curtailed budget and an eye on the city's political climate had together redefined the mission of urban community mental health. No longer could the type of long term supportive psychotherapy, as described in this book, be a major portion of the services offered. The board mandate, it was explained, did not allow for individual long term psychotherapy for the "worried well." The new goal was to provide the chronic mentally ill, and especially the now highly visible homeless mentally ill, with medications, case management, day hospital and social and vocational rehabilitation in order to make them more productive members of society and, we suspected, to reduce the public welfare and disability rolls. It was, in effect, a simultaneous cutting of services and the center's patient load. None of the patients in the urban community mental health clinic could have accurately been characterized as "worried well." Virtually all carried major psychiatric diagnoses, serious character pathology, and/or substance abuse diagnoses. Most would find it increasingly difficult to find accessible, sensitive, and caring treatment. Another area of change following the university's disengagement was that it would now be unusual to have analysts offering supervision and case conferences in the clinics.

Many of the staff of urban community mental health centers during the height of that movement have moved on-some to suburban community mental health clinics which may support and offer the kind of psychotherapy which this book addresses. Though that patient population may not be as consistently economically and socially deprived as the ghetto population described in this 
book, middle class and lower class patients alike may come from a background of emotional deprivation which recreates the altered climate for psychotherapy which is the subject of the work. It would be a mistake to assume that a patient's socio-economic class predicts the emotional richness of his formative years, just as it would be a mistake to conclude that supportive psychotherapy is applicable only in the urban ghetto. 